\title{
Characterization and in vitro Evaluation of a New Levonorgestrel Silver Liposomes
}

\author{
MATILDA RADULESCU ${ }^{1 \#, ~ C R I N E L A ~ U T E S C U ~}{ }^{1 \#, ~ F L O R I N ~ B O R C A N ² *, ~}$ \\ VICTOR DUMITRASCU ${ }^{1}$, DAN NAVOLAN ${ }^{1}$, IOANA ZINUCA PAVEL ${ }^{2}$, DANA STOIAN ${ }^{1}$ \\ ${ }^{1}$ Victor Babes University of Medicine and Pharmacy Timişoara, Faculty of Medicine, 2 Eftimie Murgu Sq., 300041, \\ Timisoara, Romania \\ 2 Victor Babes University of Medicine and Pharmacy Timișoara, Faculty of Pharmacy, 2 Eftimie Murgu Sq., 300041, \\ Timisoara, Romania
}

\begin{abstract}
Levonorgestrel is the most widely used synthetic hormone due in particular to strong progestin and anti-ovulatory effects, without estrogenic effects, being also used in hormone supportive therapy and found in preclinical studies for the prevention / occurrence of malignant processes. In order to be able to eliminate the adverse effects but to benefit at the same time from the beneficial biological effects, the posibility of obtaining effective and safe biocompatible formulations is studied. In the present research silver nanoparticles loaded with lenorgestrel were obtained and were subsequently included in a liposomal transporter system. Physico-chemical characterizations showed good stability of the liposomal systems obtained and dimensions compatible with the biological environment. In vitro data conducted on breast cells (MCF 10A and MCF7) revealed a dosedependent influence in terms of cell viability with no significant changes at low concentration of samples $(0.1 \mu \mathrm{M})$, while higher concentration was associated with a decrease of the viable breast adenocarcinoma cells especially in the case of silver nanoparticles.
\end{abstract}

Keywords: levonorgestrel, silver nanoparticles, liposomes, breast cells

\section{Introduction}

The use of synthetic hormones is necessary in different conditions, especially among women. The administration of combined oral contraceptives that contain a mixture from an estrogen derivative and a progesterone derivative is associated with the onset of venous thromboembolism due to increased serum estrogen levels in particular [1]. Newer generations of combined oral contraceptives present a higher risk of developing venous thromboembolism compared to the first generation [2]. In contrast, contraceptives based solely on progesterone derivatives do not appear to present such risks [3]. Levonorgestrel is extensively used as an active substance in certain contraceptive therapies and hormone replacement therapy. It is well known that steroid hormones are compounds that have repercussions on the endocrine gland, exerting influence on endocrine function even at extremely low concentrations [4].

To increase the stability and solubility of pharmaceutical substances for many years, different formulations are used by employing a series of macromolecules. Polyethers are polymers that have in their macromolecular structure the etheric group, some have FDA approval for use but in the pharmacological field they are useful only those that exert biodegradability. The most well-known and used such polymer is poly (ethylene glycol) (PEG) due to the advantages that make it ideal for pharmaceutical use: water solubility, non-ionic, non-toxic and biocompatible, already being approved by the FDA [5]. Liposomes were discovered decades ago but still capture the attention of researchers as being structurally distinct. They have a phospholipid structures with self-assembly role in lipid layers, which can incorporate lipophilic molecules and have an aqueous nucleus that can store hydrophilic molecules [6]. More recently, liposomes have been modified to extend the time of systemic circulation and retention of incorporated active substances. PEG molecules have proven to be

*email: fborcan@umft.ro ${ }^{\#}$ Authors with equal contribution 
extremely useful in this case, with already approved forms which are used in cancer treatment: Doxil®, Lipodox ${ }^{\circledR}$, Oncodox ${ }^{\circledR P E G}$. [7]

The aim of the current study was to obtain levonorgestrel silver nanoparticles which were subsequently incorporated into liposomes in order to obtain a compatible and effective system correlated with the biological environment. The samples obtained were characterized by the usual physico-chemical methods and were afterwards tested in vitro for a preliminary evaluation of the behavior and safety.

\section{Materials and methods}

\subsection{Materials}

The reagents used in the current study were purchased from: Sigma Aldrich (Germany) levonorgestrel (Lng) analytical standard, trisodium citrate, polyethylene glycol, lecithin, cholesterol; Merck (Germany) - silver nitrate, ethanol; Acros Organics (Belgium) - sodium lauryl sulfate. The specific materials utilized for the in vitro experiments (cell media, antibiotics, phosphate saline buffer, quantification reagents) were provided from American Type Culture Collection (ATCC, Germany), Sigma-Aldrich (Germany), Roche Diagnostics GmbH (Germany) and Thermo Fisher Scientific (USA).

\subsection{Synthesis and physico-chemical characterization}

Silver nanoparticles (Ag_NPs) were obtained by chemical synthesis based on Turkevich's process with minor modification, as described in the literature: $1 \mathrm{mM}$ silver nitrate aqueous solution was mixed with $4 \times 10^{-1} \mathrm{mM}$ trisodium citrate and $5 \times 10^{-1} \mathrm{mM}$ sodium lauryl sulfate solutions under continuous stirring until a yellow pale color specific for silver colloids appear [8,9]. In order to obtain PEGylated silver nanoparticles (Ag_NPs_PEG) PEG 400 was employed. Levonorgestrel (Lng) metallic colloids with a final concentration of $2 \times 10^{-3} \mathrm{mM}$ were synthetized with both silver nanoparticles and PEGylated silver nanoparticles by treating them with a ethanolic levonorgestrel solution. After purification, the resulting samples (Ag_NPs, Ag_NPs_PEG, Lng_Ag_NPs and Lng_Ag_NPs_PEG) were stored in the refrigerator in dark bottles.

The liposomes were obtained by thin-layer hydration method: lecithin and cholesterol were dissolved in chloroform and the mixture was stirred, then the solvent was removed and subsequently the formed film was hydrated with the colloidal silver solutions previously obtained (molar ratio drug:lecithin:cholesterol $0.15: 12.5: 1$ ). After hydration, the solutions were subjected to ultrasound to obtain the desired size, lyophilized and kept at $4-6{ }^{\circ} \mathrm{C}$ until further use.

The physico-chemical characterization of the samples obtained was realized by usual methods: UV-Vis spectroscopy (Cary $60 \mathrm{UV}-\mathrm{Vis}$ and Secomam UviLine 9400), SEM-EDAX determination with EDAX detection on SEM, by utilizing an EDAX detector with FEI Quanta 250 microscope, TEM evaluation using a FEI Tecnai 12 Biotwin microscope and zeta analysis (Zetasizer Nano ZS system, Malvern Instruments).

\subsection{In vitro studies}

The experiments were conducted using two breast cell lines purchased from ATCC as frozen items: MCF 10A (ATCC® CRL-10317 ${ }^{\mathrm{TM}}$ ) and MCF7 (ATCC ${ }^{\circledR}$ HTB-22 ${ }^{\mathrm{TM}}$ ). The cells were grown and multiplied according to the manufacturer's specifications: MCF 10A with DMEM:F12 supplemented with EGF, insulin, hydrocortisone, FCS, and antibiotic mixture and MCF7 with EMEM supplemented with insulin and FBS. The cells were used in experiments only after reached a confluence of 85-90\%.

The cell viability was assessed by MTT assay, as presented in the literature [8-10]: (1) cells were seeded in specific microplate (96 well) using the specific media for each cell type and allowed to attach; (2) after $24 \mathrm{~h}$, the medium was replaced and the cells were treated with two concentrations of the samples $(0.1$ and $1 \mu \mathrm{M})$ for $24 \mathrm{~h}$; (3) the MTT reagent was added and cells were incubated for $4 \mathrm{~h}$; (4) samples were spectrophotometrically examined at $570 \mathrm{~nm}$ at a microplate reader (xMark Spectrophotometer - BioRad). 


\subsection{Statistical analysis}

The GraphPad Prism 7 software was used for data processing and presentation and one-way ANOVA test was selected to establish the statistical differences followed by Tukey's post-test and $\mathrm{p}$ values were: $* \mathrm{p}<0.1,{ }^{*} \mathrm{p}<0.01, * * * \mathrm{p}<0.001$ and $* * * * \mathrm{p}<0.0001 v s$. control cells. The data are presented as the mean \pm standard deviation (SD).

\section{Results and discussions}

Silver nanoparticles loaded with levonorgestrel were obtained by chemical synthesis in order to better control their size. UV-Vis spectra were used during the syntheses to confirm the formation of silver nanoparticles in the form of colloidal solutions. The elemental composition of silver colloids by the EDAX analysis was conducted (Figure 1). The elements present in the unloaded silver nanoparticles samples were $\mathrm{C}, \mathrm{O}, \mathrm{N}, \mathrm{Na}$ and $\mathrm{Ag}$ expressed in weight percent (Wt\%) or atomic percent (At.\%) (Table 1).
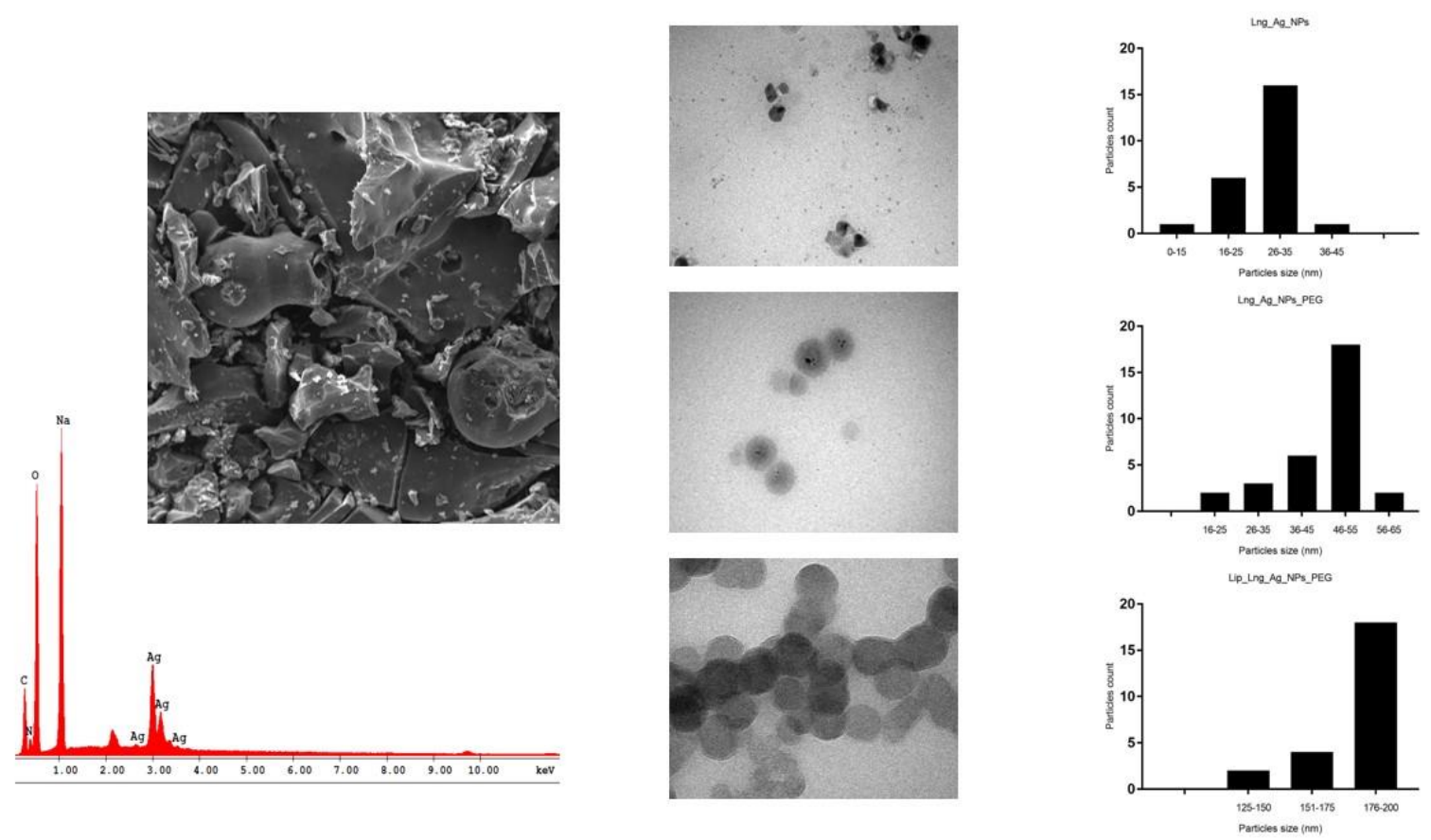

Figure 1. Energy dispersive X-ray spectra and SEM image of lyophilised AgNPs together with TEM images and particle size distributions of levonorgesyrel silver nanoparticlis, PEGylated particles and liposomal structure.

Table 1. Elemental composition of basic silver colloids

\begin{tabular}{ccccccc}
\hline Element & Wt \% & At \% & K-Ratio & $\mathbf{Z}$ & A & F \\
\hline C K & 20.81 & 29.33 & 0.0609 & 1.0365 & 0.2819 & 1.0006 \\
\hline N K & 5.40 & 6.52 & 0.0107 & 1.0288 & 0.1930 & 1.0013 \\
\hline O K & 41.94 & 44.37 & 0.0889 & 1.0219 & 0.2073 & 1.0005 \\
\hline $\mathrm{NaK}$ & 25.52 & 18.79 & 0.0565 & 0.9600 & 0.2306 & 1.0002 \\
\hline $\mathrm{AgL}$ & 6.33 & 0.99 & 0.0639 & 0.7916 & 1.2751 & 1.0000 \\
\hline Total & 100.00 & 100.00 & & & \\
\hline
\end{tabular}

In order to assess the stability of the samples zeta potential was determined and the data obtained were satisfactory the values being negative and located in the range $39 \mathrm{mV}-19 \mathrm{mV}$ with the lowest values for liposomal systems (Table 2). Size of the samples obtained are biocompatible with the biological environment and are presented in the Table 2. 
Table 2. Physico-chemical properties of silver nanoparticles, PEGylated silver nanoparticles, levonorgestrel metallic colloids and their liposomal formulations

\begin{tabular}{cccc}
\hline \multirow{2}{*}{ Sample } & \multicolumn{3}{c}{ Parameter } \\
\cline { 2 - 4 } & Particles size $(\mathrm{nm})$ & PDI $(\%)$ & Zeta potential $(\mathrm{mV})$ \\
\hline Ag_NPs & 27 & 0.210 & -39 \\
\hline Lng_Ag_NPs & 32 & 0.186 & -27 \\
\hline Ag_NPs_PEG & 52 & 0.241 & -32 \\
\hline Lng_Ag_NPs_PEG & 55 & 0.199 & -38 \\
\hline Lip_Ag_NPs & 138 & 0.188 & -19 \\
\hline Lip_Ag_NPs_PEG & 144 & 0.236 & -22 \\
\hline Lip_Lng_Ag_NPs & 157 & 0.192 & -21 \\
\hline Lip_Lng_Ag_NPs_PEG & 186 & 0.203 & -22 \\
\hline
\end{tabular}

Hormonal changes have an impact on the female mammary gland and decreasing hormone exposure decreases the risk of breast cancer, but there is also a theory that increased hormone exposure may increase the risk of disease. There are studies that have shown the mitogenic effects of estrogen and progesterone related to cancer initiation, but also effects that amplify the development of preexisting tumor formations through the actions of estrogen metabolites. Some studies suggest that systemic progesterone treatment contributes to increased expression levels of reductive enzymes compared to oxidative ones, which results in a possible increase of estrogen hormones and thus increases the proliferation of breast epithelial cells. [11,12]

In order to assess the cytotoxic impact of levonorgestrel silver nanoparticles and their liposomal systems on breast epithelial cells - MCF 10A, there were selected two concentrations $0.1 \mu \mathrm{M}$ and 1 $\mu \mathrm{M}$, respectively for $24 \mathrm{~h}$. The data obtained revealed that at $0.1 \mu \mathrm{M}$ no significant influence on cell viability was noted for $24 \mathrm{~h}$ (data not shown). At a concentration of $1 \mu \mathrm{M}$, there was a slight decrease in cell viability after treatment with Ag_NPs (viability 93\%), Lng_Ag_NPs (viability 94\%) and Lip_Ag_NPs (viability 94\%) (Fig. 2). The cytotoxic potential of the obtained samples on human adenocarcinoma breast cells has been conducted on MCF7 cells which were stimulated with the same concentrations used in non-cancer cells (MCF 10A) $0.1 \mu \mathrm{M}$ and $1 \mu \mathrm{M}$, respectively. The viability was more or less statistically influenced by all the samples tested at the highest concentration as follows: $\sim 90 \%$ for Ag_NPs and Lip_Ag_NPs_PEG, $\sim 91 \%$ for Lip_Lng_Ag_NPs_PEG, $\sim 92 \%$ for Ag_NPs_PEG, $293 \%$ for Lip_Ag_NPs, $94 \%$ for Lip_Lng_Ag_NPs (Figure 3).

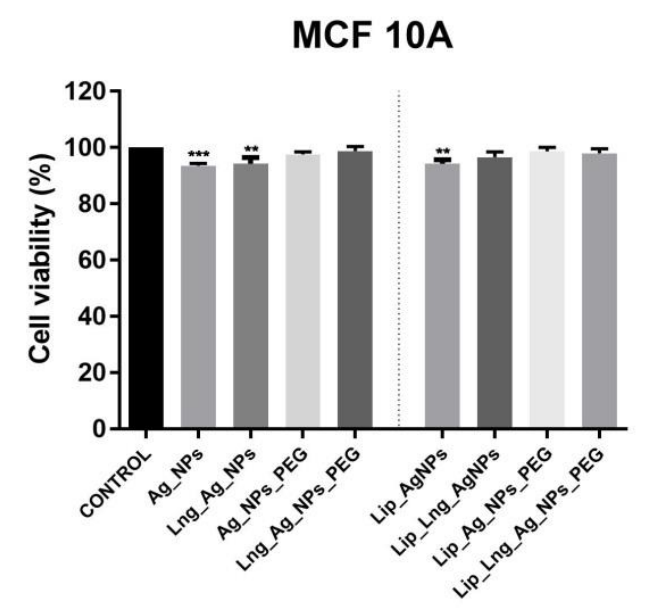

Figure 2. Cytotoxic-related impact of levonorgestrel silver nanoparticles and their liposomal systems on breast epithelial cells - MCF 10A related to control cells (untreated) based on MTT assay. All experiments were conducted in triplicate 


\section{MCF7}

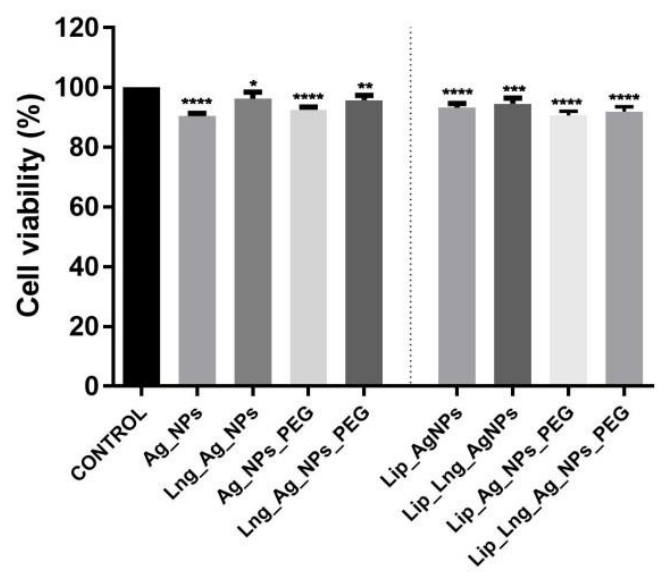

Figure 3. Cytotoxic-related impact of levonorgestrel silver nanoparticles and their liposomal systems on breast adenocarcinoma cells - MCF7 related to control cells (untreated) based on MTT assay.

All experiments were conducted in triplicate

Currently, the action of pharmaceutical and medical products based on synthetic progestatives in the initiation and development of breast cancer is not sufficiently known due to studies using small samples, different types of progestins, frequency and use, environmental factors, genetic factors, etc. [13] Finding specific, biocompatible and no side effects formulations is necessary for effective and safe administration of patients' health. One of the most important parameters in the use of liposomes in the biomedical field is their size which manifests a direct influence on the half-life of the circulation in the release of active substances. The methods used to obtain liposomes involve the passive loading of the active substances. [14] Due to the complex mechanisms that occur in the biological environment, the association between the active substances, the metal nanoparticles and the carriers themselves is still a challenge for the specialists in these fields. The gold nanoparticles have been associated with liposomes but their release rate is still optimized despite the complexity of the methods of obtaining and optimizing the parameters. [15] In the study conducted by Yusuf and collaborators, liposomes loaded with silver nanoparticles (for use in anticancer therapies) suppressed the generation of reactive oxygen species, depleted GSH levels, damaged DNA and all of these could ultimately lead to cell death. [16]

\section{Conclusions}

The data from the present study provide that levonorgestrel silver nanoparticles and their liposomal systems meet the requirements for use in the biomedical field based on their stability and size. Preliminary testing of the obtained systems was performed on two mammary cell lines (non-tumoral MCF 10A and tumoral - MCF7) to evaluate the activity at low concentrations taking into account that data from the literature often use concentrations that prove cytotoxicity on tumor cell lines but does not use comparisons with healthy lines. There was a slight reduction in the viability of the tumor cells, which varied statistically according to the components of the sample, those with levonorgestrel having a lower influence compared to those without these substance.

Acknowledgments: The in vitro experiments were conducted within the Center of Pharmacotoxicological evaluations from the Faculty of Pharmacy, "Victor Babes" University of Medicine and Pharmacy, Timisoara. 


\section{References}

1. KOZUKA, T., TAMURA, S., KAWAMURA, N., NAKATA, Y., HASEBE, R., MAKIYAMA, A., et al., Progestin isoforms provide different levels of protein S expression in HepG2 cells, Thromb. Res., 145, 2016, 40-45. doi:10.1016/j.thromres.2016.07.007

2. LIDEGAARD, O., MILSOM, I., GEIRSSON, R.T., SKJELDESTAD, F.E., Hormonal contraception and venous thromboembolism, Acta Obstet. Gynecol. Scand., 91(7), 2012, 769-778.

3. MANTHA S., KARP R., RAGHAVAN V., TERRIN N., BAUER K.A., ZWICKER J.I., Assessing the risk of venous thromboembolic events in women taking progestin-only contraception: a meta-analysis, $\mathrm{Br}$. Med. J., 345, 2012, e4944

4. EBRAHIMPOUR, B., YAMINI, Y., SEIDI, S., TAJIK, M., Nano polypyrrole-coated magnetic solid phase extraction followed by dispersive liquid phase microextraction for trace determination of megestrol acetate and levonorgestrel, Anal. Chim. Acta., 885, 2015, 98-105.

5. ALCONCEL, S.N.S., BAAS, A.S., MAYNARD, H.D., FDA-approved poly(ethyleneglycol)-protein conjugate drugs., Polym. Chem., 2, 2011, 1442-1448.

6. PATTNI, B.S., CHUPIN, V.V., TORCHILIN, V.P., New developments in liposomal drug delivery. Chem. Rev., 115, 2015, 10938-10966.

7. ENGLERT, C., BRENDEL, J.C., MAJDANSKI, T.C., YILDIRIM, T., SCHUBERT, S., GOTTSCHALDT, M., WINDHAB, N., SCHUBERT, U.S., Pharmapolymers in the 21 st century: Synthetic polymers in drugdelivery applications, Prog. Polym. Sci., 87, 2018, 107-164.

8. DANCIU, C., PINZARU, I., CORICOVAC, D., ANDRICA, F., SIZEMORE, I., DEHELEAN, C., BADERCA, F., LAZUREANU, V., SOICA, C., MIOC, M., RADEKE, H., Betulin silver nanoparticles qualify as efficient antimelanoma agents in in vitro and in vivo studies, Eur. J. Pharm. Biopharm., 134, 2019, 1-19.

9. PINZARU, I., CORICOVAC, D., DEHELEAN, C., MOACA, E.-A., MIOC, M., BADERCA, F., SIZEMORE, I., BRITTLE, S., MARTI, D., CALINA, C.D., TSATSAKIS, A.M., SOICA, C., Stable PEGcoated silver nanoparticles - A comprehensive toxicological profile, Food Chem. Toxicol., 111, 2018, 546556.

10. ANDOR, B., TISCHER, A.A., BERCEANU-VADUVA, D., LAZUREANU, V., CHEVERESAN, A., POENARU, M., Antimicrobial Activity and Cytotoxic Effect on Gingival Cells of Silver Nanoparticles Obtained by Biosynthesis, Rev. Chim., 70(3), 2019, 781-783.

11. SIVIK, T., JANSSON, A., Progesterone and levonorgestrel regulate expression of 17ßHSD-enzymes in progesterone receptor positive breast cancer cell line T47D, Biochem. Biophys. Res. Commun., 422(1), 2012, 109-113. doi:10.1016/j.bbrc.2012.04.116

12. SCHOONEN, W.G., JOOSTEN, J.W., KLOOSTERBOER, H.J., Effects of two classes of progestagens, pregnane and 19-nortestosterone derivatives on cell growth of human breast tumor cells: II. T47D cell lines, J. Steroid Biochem. Mol. Biol. 55, 1995, 439-444.

13. SAMSON, M., PORTER, N., OREKOYA, O., HEBERT, J.R., ADAMS, S.A., BENNETT, C.L., STECK, S. E., Progestin and breast cancer risk: a systematic review, Breast Cancer Res. Treat. 155(1), 2016, 3-12.

14. ÇAĞDAŞ, M., SEZER, A.D., BUCAK, S., Application of Nanotechnology in Drug Delivery. Liposomes as Potential Drug Carrier Systems for Drug Delivery, IntechOpen, DOI: 10.5772/58459. Available from: https://www.intechopen.com/books/application-of-nanotechnology-in-drug-delivery /liposomes-as- potential-drug-carrier-systems-for-drug-delivery

15. SEYNHAEVE, A.L.B., AMIN, M., HAEMMERICH, D. VAN RHOON, G.C., TEN HAGEN, T.L.M., Hyperthermia and smart drug delivery systems for solid tumor therapy, Adv. Drug Deliv. Rev., 2020, https://doi.org/10.1016/j.addr.2020.02.004

16. YUSUF, A., CASEY, A., Liposomal encapsulation of silver nanoparticles (AgNP) improved nanoparticle uptake and induced redox imbalance to activate caspase-dependent apoptosis, Apoptosis, 25(12), 2020, 120-134.

$\overline{\text { Manuscript received: } 9.03 .2020}$ 